\title{
Erratum to: Low IgA and IgM is Associated with a Higher Prevalence of Bronchiectasis in Primary Antibody Deficiency
}

\author{
John P. Hodkinson ${ }^{1}$ - Catherine Bangs ${ }^{2}$ - Andrea Wartenberg-Demand ${ }^{3}$. \\ Artur Bauhofer ${ }^{3} \cdot$ Patrick Langohr $^{3}$ • Matthew S. Buckland ${ }^{4}$. David Guzman ${ }^{5}$. \\ Patrick F. K. Yong ${ }^{6} \cdot$ Sorena Kiani-Alikhan ${ }^{6}$
}

Published online: 6 April 2017

(C) Springer Science+Business Media New York 2017

\section{Erratum to: J Clin Immunol}

DOI 10.1007/s10875-017-0381-y

The original version of this article unfortunately contained a mistake. The family name of Andrea Wartenberg-Demand was misspelled as Watenberg-Demand. The original article was corrected.

The online version of the original article can be found at http://dx.doi.org/ 10.1007/s10875-017-0381-y

\footnotetext{
Sorena Kiani-Alikhan

skiani@nhs.net

1 Biotest UK Ltd, Birmingham, UK

2 Central Manchester University Hospitals NHS Foundation Trust, London, UK

3 Biotest AG, Dreieich, Germany

4 Barts Health NHS Trust, London, UK

5 University College London, London, UK

6 Royal Surrey and Frimley Park NHS Foundation Trusts, London, UK
} 